\title{
Caminhos da história e da memória: a Universidade Aberta da Terceira Idade da UERJ
}

\author{
History and memory ways: UERJ's Open University for Studies on the Elderly

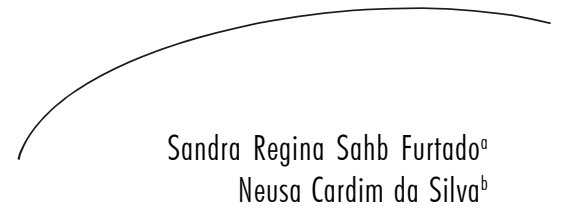

\section{Resumo}

Apresenta o Projeto Memória da Universidade Aberta da Terceira Idade da Universidade do Estado do Rio de Janeiro (UnATI/UERJ), que está sendo desenvolvido pelo Centro de Referência e Documentação sobre Envelhecimento (CRDE). O Projeto tem como principal objetivo organizar e preservar a Memória da UnATI, e como objetivos específicos resgatar os documentos históricos e criar uma base de dados com os materiais informacionais indexados e registrados, além de coletar depoimentos orais para compor o acervo. $\mathrm{O}$ artigo traz relato do histórico de criação da UnATI/UERJ no cenário da Universidade, citando suas principais ações no campo do envelhecimento. Discorre sobre o CRDE com enfoque na sua origem, atividades e produtos, com destaque para o Projeto. Contextualiza-o tendo como aporte teórico a memória e a história, e como metodologia a revisão de literatura, visitas técnicas, coleta de documentos, sua análise e seu processamento técnico. $\mathrm{O}$ modelo UnATI desperta a atenção de instituições e pesquisadores, assim o resgate da sua memória preserva esse modelo e fornece subsídios para outras iniciativas.

\section{Abstract}

This paper presents the Memory Project, of the Open University for Studies on the Elderly, Rio de Janeiro State University (UnATI/UERJ) developed by the Reference and Documentation on Ageing Center (CRDE). The

\footnotetext{
Correspondência / Correspondence

Sandra Regina Sahb Furtado

CRDE/UnATI/UERJ

Rua São Francisco Xavier, $524-10^{\circ}$ and, blobo F

20559-900 - Rio de Janeiro, RJ, Brasil
}

Artigo produzido a partir da primeira fase do Projeto Memória da Universidade Aberta da Terceira Idade, da Universidade do Estado do Rio de Janeiro, concluída em fevereiro de 2008.

\author{
Palavras-chave: \\ universidades; \\ projetos; História
}


Project's main goal is to organize and preserve UnATI's memory and the specific aims are to bring back historical documents and create a database with indexed and registered informational material, besides collecting oral depositions to compose the collection. The paper brings historical reports on the creation of UnATI/UERJ within the University, quoting its main actions in the ageing field. It focuses on the creation of CRDE, activities and products, with prominence to the Project. The project highlights the theoretical support with memory and history, using the literature review methodology, technical visits, documents' collection, its analysis its technical procedure. The UnATI model attracts the attention of institutions and researchers, so its memory is brought back preserving this model and subsidizes other initiatives.
Key words: universities, projects, History.
INTRODUÇÃO

Como uma sociedade, qualquer que seja, poderia existir, subsistir, tomar conhecimento de si mesma, se ela não considerasse um conjunto de acontecimentos do presente e do passado, se ela não pudesse reconstruir o curso do tempo e recuperar incessantemente os traços que deixou de si mesma? Halbwachs (apud Santos). ${ }^{1}$

Existe uma considerável quantidade de trabalhos publicados a respeito do envelhecimento, nos quais são apresentadas estatísticas que apontam para a necessidade de aprofundar os conhecimentos sobre os idosos, no âmbito da saúde, da cultura, da política e da economia. Segundo a Organização das Nações Unidas (ONU), a população de idosos vem crescendo no mundo todo e é previsto que no ano de 2047 haja mais pessoas idosas do que pessoas jovens no mundo. ${ }^{2}$

Isso contribui para a questão do envelhecimento ser muito discutida na comuni- dade científica e em vários segmentos da sociedade. Pesquisadores de diferentes disciplinas são estimulados a estudar, debater, consumir e produzir informações sobre os idosos. Dito de outro modo, o tema envelhecimento é interdisciplinar e está atraindo a atenção de estudantes e profissionais em escala proporcional à nova demanda da sociedade moderna.

Sobre a velhice na sociedade industrial, em 1979, Bosi destacou a fragilidade do ser envelhecido diante do novo tempo: "Para que nenbuma forma de bumanidade seja excluida da bumanidade é que as minorias têm lutado, que os grupos discriminados têm reagido. A mulher, o negro, combatem pelos seus direitos, mas o velho não tem armas. Nós é que temos de lutar por ele".

À frente de seu tempo, o Professor Dr. Américo Piquet Carneiro, em meados da década de 1970, identificou a importância do assunto e, consciente de seu dever como médico e educador, abraçou a causa de criar um espaço para os idosos num ambiente universitário. Dessa forma, em 1993, inaugurou-se, na Universidade do Estado do Rio 
de Janeiro (UERJ), a Universidade Aberta da Terceira Idade (UnATI), constituindo um marco no atendimento ao idoso, nas questões de saúde (física e psicológica), de cultura, de recreação e lazer. Ao longo desses quinze anos, a UnATI consolidou-se como centro de referência na área do envelhecimento, subsidiando o desenvolvimento do conhecimento científico em Geriatria e Gerontologia.

A par desse patrimônio construído, foi elaborado um projeto" com o objetivo de registrar a origem histórica da UnATI e fazer emergir sua memória institucional e social, inventariando os registros do seu processo de criação, para preservar o passado próximo dessa trajetória, impresso nos seus documentos, nas suas imagens, pesquisas e relatos da comunidade. São esses documentos históricos que refletem a memória coletiva construída no cotidiano daqueles que atuaram no mesmo espaço social - no caso, a UnATI.

O objetivo deste artigo é apresentar o Projeto Memória da UnATI - em curso na Universidade -, enfocando os antecedentes históricos que lhe serviram de base e $\mathrm{o}$ referencial teórico que o sustenta.

\section{ANTECEDENTES HISTÓRICOS}

No final da década de 1970, o eminente Professor Dr. Américo Piquet Carneiro ministrou a aula inaugural da UERJ sobre o tema Atualidade e envelhecimento dos povos, ${ }^{* * *} \mathrm{em}$ que discorreu sobre a questão do envelhecimento humano no mundo, apresentando dados e estudos demográficos do envelhecimento com análises e estimativas, concluindo: "O envelhecimento populacional será, seguramente, um dos maiores problemas sociais a se enfrentar, em futuro próximo, em todo o mundo. É urgente, portanto, que os governos e as universidades comecem a dar atenção a essa grave questão, organizando centros ou institutos para o estudo dos aspectos biológicos e sociais do envelhecimento, elaborando programas para recuperaşão e utilizaçãa da imensa força de trabalho que representa uma grande percentagem de pessoas que se aposentam cedo, ainda com muito vigor físico e intelectual que o país não pode desprezar". ${ }^{4}$

Enquanto atuava no Hospital Universitário Pedro Ernesto (HUPE), o Prof. Piquet Carneiro coordenou o Programa de Estudos, Debates, Pesquisa e Assistência sobre a Terceira Idade, e também a elaboração do projeto para implantação do Núcleo de Atenção ao Idoso - NAI/ UnATI. Em 1990, no HUPE, fundou-se o NAI, que deu origem à atual Universidade Aberta da Terceira Idade - UnATI. O objetivo era que o novo espaço se constituísse em (...) um grande Centro de Convivencia voltado para o estudo da população idosa que, além de compreender uma unidade de saúde de referência, pudesse ser um lócus de formação qualificada de profissionais de saúde e áreas correlatas, e de produção e disseminação de conbecimento por meio do desenvolvimento de pesquisas. Um centro que prestasse assistência e oferecesse serviços de natureza diversa a idosos de diferentes faixas etárias, gêneros, etnias,

\footnotetext{
Projeto Memória da Universidade Aberta da Terceira Idade, elaborado por Sandra Sahb, em 2005.

** Aula magna na Assembléia Universitária de abertura do ano letivo, em 06 de março de 1979.
} 
estratos sociais e niveis educacionais e culturais, sempre norteados pela excelência das alternativas oferecidas. Enfim, um Centro de Convivência e excelência no interior da universidade pública. ${ }^{5}$

A criação do Programa Universidade da Terceira Idade deu-se através do AE-020/ Reitoria/92, tendo sido inaugurado em 1993, inicialmente vinculado ao Instituto de Medicina Social (IMS) da UERJ. O Prof. Américo Piquet Carneiro pôde ver seu projeto sendo executado, porém, no ano de 1992, a UnATI perdeu o seu grande idealizador e fundador. A continuidade do Programa ficou a cargo dos profissionais que pertenciam ao grupo de estudos, e o Professor Dr. Renato Peixoto Veras assumiu a direção da entidade.

Em 1994, a UnATI tornou-se, oficialmente, um Núcleo de Ensino, Pesquisa e Extensão, ratificando a excelência do programa e a receptividade das comunidades acadêmica e externa." Dois anos depois, a UnATI ampliou sua função assistencial, com a criação da Clínica de Cuidado Integral à Pessoa Idosa (CIPI), localizada na Policlínica Piquet Carneiro, também pertencente à UERJ. Nesse serviço, à semelhança do que é desenvolvido no NAI, uma equipe multidisciplinar presta assistência médica e realizam-se atividades de promoção de saúde e pesquisa. Os dois ambulatórios da UnATI atendem aos idosos da comunidade, independentemente de serem seus alunos. Além do ambulatório do Núcleo de Atenção ao Idoso, o NAI abrange os Proje- tos de Promoção da Saúde no Envelhecimento; de Assistência e Estudos em Neurogeriatria; Atenção Integral ao Idoso Internado; Atenção ao Idoso Asilado e um consultório dentário.

A UnATI desenvolve atividades de ensino, pesquisa e extensão, através de ações baseadas em pressupostos gerontológicos de natureza sócio-educativa, e conta com a participação de faculdades, institutos e unidades da UERJ, na oferta de mais de 55 cursos à população, distribuídos em cem turmas que concentram cerca de dois mil e quinhentos idosos por ano.** Os alunos participam dessa prática sócio-político-pedagógica, na qual se vivencia a experiência coletiva do processo de envelhecimento. Em sintonia com a concepsão de cursos e atividades para os idosos, esteve sempre presente a preocupação da qualificação e formação de recursos humanos capazes de lidar com este segmento etário. Seria contraditório lidar com as demandas provenientes desta população, no interior de uma universidade, sem o necessário estímulo à formação qualificada dosjovens que estão se graduando em diversas áreas do conhecimento e que irão atuar em uma sociedade marcada pelo crescente envelhecimentopopulacional. ${ }^{5}$

Para dar suporte às pesquisas foi criado, em 1999, o Centro de Referência e Documentação sobre Envelhecimento (CRDE/UnATI), com o objetivo de promover a disseminação do conhecimento, identificar, coletar, custodiar, preservar e organizar acervos documentais provenientes de instituições e de pesquisadores que atuam nas áreas de Geriatria e Gerontologia.

Universidade do Estado do Rio de Janeiro. Reitoria. Resolução n. 002/94 cria o Núcleo de Ensino, Pesquisa e Extensão da UnATI.

"** Dados do anuênio 2007. 
O curso de Especialização em Geriatria e Gerontologia administrado pela UnATI, aprovado e criado em 2004, fomenta pesquisas, investe na produção científica e capacita profissionais no campo de atuação do envelhecimento humano.

A qualidade da produção científica da UnATI se revela nas citações de trabalhos publicados sobre o envelhecimento, representando grande contribuição à produção científica nacional da área.

O reconhecimento internacional do Programa foi comprovado em 2005, quando a Organização Mundial da Saúde (OMS) e a Organização Pan-Americana da Saúde (OPAS) designaram a UnATI como Centro Colaborador da OPAS/OMS para a Terceira Idade e Saúde.

O Programa UnATI está em pleno desenvolvimento, e novas ações vão sendo incorporadas para o cumprimento de seus princípios, de prestar serviços de qualidade, com atividades de relevância social destinada à população idosa e que atendam aos interesses individuais, considerando suas histórias e trajetórias de vida.

A visão de um médico e educador levou a Universidade a construir um espaço que congrega estudantes, profissionais e pesquisadores de várias áreas, para desenvolver atividades de ensino, pesquisa e assistência nos campos da Geriatria e Gerontologia, beneficiando, principalmente, a comunidade idosa do Estado do Rio de Janeiro e constituindo-se num perfeito complexo de integração social.

\section{CENTRO DE REFERÊNCIA E DOCUMENTAÇÃO SOBRE ENVELHECIMENTO (CRDE)}

A implementação do Centro de Referência e Documentação sobre Envelhecimento da UnATI-CRDE aconteceu num importante cenário histórico, pois o ano de 1999 foi considerado, pela Organização das Nações Unidas (ONU), o Ano Internacional do Idoso, quando então recomendou que, em todos os países membros, fossem realizados eventos alusivos ao tema.

O CRDE tem como missão promover o acesso e a disseminação da informação, dar suporte informacional às atividades de pesquisa na área do envelhecimento humano, orientando os usuários de acordo com seus interesses próprios, independentemente de sua localização. Possui acervo especializado em Geriatria e Gerontologia, que reúne documentos de diversas tipologias e suportes. Em destaque, mantém também publicações não-científicas destinadas aos alunos da Terceira Idade. Seguindo os moldes das Bibliotecas da Rede Sirius - Rede de Bibliotecas da UERJ -, oferece aos usuários os serviços de catalogação na fonte, busca bibliográfica, comutação bibliográfica, normalização, orientação e treinamento de usuário.

O CRDE também responde pelo periódico Revista Brasileira de Geriatria e Gerontologia (RBGG) - continuação do título da revista Textos sobre Envelhecimento, criada em 1998 - que tem por objetivo publicar produção científica no âmbito da gerontogeriatria, promovendo a disseminação desse conhecimento e contribuindo, dessa 
forma, para o aprofundamento das questões relativas ao bem-estar e à saúde da população idosa. É indexada em bases nacionais e internacionais, como EDUBASE, LATINDEX e LILACS.

Tanto a revista quanto outros produtos do CRDE podem ser acessados pela Internet, através do endereço eletrônico da UnATI (www.unati.uerj.br), que possui um link para a Biblioteca. $\mathrm{O}$ acervo em meio eletrônico inclui a Base Acervo, que utiliza a metodologia LILACS para o registro, indexação e localização das publicações existentes na biblioteca: livros; capítulos de livros; artigos de revistas; folhetos entre outros, e a Base de Teses Brasileiras sobre Envelhecimento, que arrola a produção acadêmica em âmbito nacional.

O CRDE é Centro Cooperante do Sistema Latino-Americano e do Caribe de Informações em Ciências da Saúde (BIREMEOPAS-OMS), através de Convênio assinado em 1999, no qual, entre outras responsabilidades, compromete-se a coletar literatura gerada, em nível institucional, na área de Geriatria, Gerontologia e Envelhecimento, e a processar a literatura coletada segundo a metodologia desenvolvida pela BIREME para a base de dados LILACS. Esse convênio inclui a participação no Serviço de Cópia de Documentos (SCAD), o que favorece a reprodução dos documentos disponíveis na base, atendendo, de forma ágil, às demandas dos usuários.

$\mathrm{O}$ atendimento ao público é feito por bibliotecários e funcionários treinados para realizar pesquisas utilizando bases de dados das áreas das ciências da saúde, humanas e so- ciais, bem como através do Portal de Periódicos CAPES, ${ }^{6}$ que atualmente possui 11.400 periódicos indexados e em texto completo.

Em resposta às preocupações manifestadas pela sociedade na área do envelhecimento e à crescente demanda de usuários em busca de informações relacionadas aos programas existentes voltados para os idosos, o CRDE incluiu, em suas metas, a elaboração do Projeto Memória UnATI/UERJ.

\section{MEMÓRIA E HISTÓRIA}

Para a elaboração do Projeto Memória da UnATI, inicialmente foi feito levantamento bibliográfico, com o objetivo de identificar, na literatura, elementos representativos para reflexão sobre envelhecimento, memória, história e memória institucional.-16

Por extensão à valorização do envelhecimento e do passado, a memória é outra questão que vem sendo abordada em diferentes áreas do conhecimento, por seus aspectos cognitivos ou, enquanto representação social, pelas lembranças individuais ou coletivas.

Segundo Pollak, ${ }^{17}$ os elementos constitutivos da memória individual ou coletiva são, em primeiro lugar, os acontecimentos vividos pessoalmente, e, em segundo lugar, os acontecimentos vividos pelo grupo ou pela coletividade à qual a pessoa pertence. Este último ele descreve como "acontecimentos dos quais a pessoa nem sempre participou mas que, no imaginário, tomaram tamanho relevo que, no fim das contas, é quase impossível que ela consiga saber se participou ou não..." 
Nos dias de hoje, a memória também se apresenta como uma necessidade de buscar, no passado, dados que possam embasar o tempo presente. A lembrança individual de um fato, num determinado tempo e lugar, compõe uma história, quando esta coincide com a de outra pessoa ou de um grupo de pessoas.

Para Santos, ${ }^{1}$ as memórias, imagens e identidades construídas sempre apresentam lacunas, porque se referem às múltiplas experiências de vidas individuais ou coletivas, que não se encontram parados no tempo, mas em permanente transformação. Entendemos que o significado da memória é demasiado intricado, porque as lembranças e esquecimentos são variáveis de acordo com a história de cada um. Assim, o arquivo pessoal de um indivíduo, trazido pelas lembranças de sua memória, quando situados num determinado tempo e lugar e identificados ou lembrados por outros, dentro do mesmo contexto, formam a história.

Halbwachs ${ }^{18}$ apresenta uma clara distinção entre história e memória. Para ele, a história é um quadro de mudanças, e por isso o historiador fixa seu olhar sobre o conjunto, e não passam muitos anos sem que, dentro de uma região desse conjunto, alguma transformação se produza. Neste sentido, afirma que o que importa para a história são os grupos de fora. Já a memória coletiva analisa o mesmo grupo registrando as modificações de suas relações. "A memória coletiva, ao contrário, é o grupo visto de dentro, e durante um período que não ultrapassa a duração média da vida bumana, que lhe é, frequentemente, bem inferior. Ela apresenta ao grupo um quadro de si mesmo que, sem dívida, se desenrola no tempo, já que se trata de seu passado, mas de tal maneira que ele se reconhece sempre dentro dessas imagens sucessivas [...]”.

Quanto mais cedo se procede ao ato de registrar a memória, menor a dificuldade de recompor seus detalhes, principalmente quando se pode contar com a lembrança dos participantes. O tempo sedimenta eventos e fatos de forma desordenada, mas a memória se presta a acolhê-los, tornando possível organizar esse tempo pretérito, ainda que envolto em subjetividades.

Trazer à tona o processo de criação e construção da UnATI permitirá reafirmar os seus propósitos, de acordo com os conceitos estabelecidos em sua concepção e, assim, através da lembrança do passado e do reconhecimento da sua identidade, compreender sua trajetória.

Durante muitos séculos, a história vivida foi transmitida de geração a geração por meio da oralidade, pela narração de fatos e feitos; a palavra era fonte crível e respeitada. Esse status começa a ser alterado com o aparecimento da escrita, pois o que se transmitia ao escrever passou a ser condicionado a uma racionalidade objetiva. Porém, por outros longos séculos, a escrita conviveu mais amiúde com a tradição oral, até a invenção da imprensa.

Com a introdução do pensamento científico, postulava-se que a ciência era a única forma de conhecimento possível para se chegar a verdades absolutas e objetivas; a história construída a partir da memória não encontrava respaldo na produção do conhecimento científico. Somente no século XX, olhares mais críticos se voltavam 
sobre a história. "Nesse momento se incorporam conceitos de outras ciências sociais como a filosofia e a antropologia, assim como dados da experiência individual e coletiva, inaugurando-se uma concepşão do tempo a partir da observação de longos periodos, a "bistória de longa duração". Incorporando as noções de tempo vivido, de tempos relativos e múltiplos em contraposição a um factualismo já insuficiente para a apreensão dos fenômenos históricos, estes serão, finalmente, problematizados em um contexto mais amplo de rupturas, transformações sociais e mudanças culturais". ${ }^{19}$

Freitas e $\mathrm{Braga}^{19}$ afirmam ainda que " $a$ memória não pode mais ser vista como um processo parcial e limitado de lembrar fatos passados, de valor acessório para as ciências bumanas". E acrescentam que "A história não pode ter a pretensão de estabelecer os fatos como de fato ocorreram, e por isso coexistem, não obstante, várias leituras possiveis sobre a utilização da memória para a interpretação da história".

No início da década de 50, a história oral passou a ser utilizada como técnica de documentação histórica. Para Meihy e Holanda $^{20}$ a entrevista é história oral em sentido exato. "História oral é um recurso moderno usado para a elaboração de registros, documentos, arquivamento e estudos referentes à experiência social de pessoas e grupos. Ela é sempre uma história do tempo presente e também reconhecida como história viva."

Nesse contexto, coletar depoimentos daqueles que acompanharam o processo de construção do Programa e daqueles que efetivamente usufruem seus serviços constitui um processo de resgate da memória. A utilização de depoimentos orais deve ser vista como um recurso complementar no conjunto do resgate histórico da UnATI.

\section{O PROJETO MEMÓRIA UNATI}

A UnATI completa 15 anos e, em seu curso de vida, já se encontram muitas contribuições e experiências que precisam ser recuperadas e registradas, inclusive como forma de estímulo à continuidade do ato de resgatar as atividades relevantes que determinaram sua passagem.

A demanda por informações e as questões relacionadas ao modelo da UnATI/ UERJ, desde o seu processo de criação até a atual estrutura de atendimento a sua comunidade, têm despertado a atenção dos interessados no campo do envelhecimento. Por si só, esta razão seria suficiente para justificar a criação do Projeto Memória da UnATI/UERJ, mas, além desta, temos que considerar dois anteprojetos elaborados anteriormente para organizar e preservar a memória da UnATI : o anteprojeto para a criação do Centro de Memória da UnATI/ UERJ," que tinha como objetivo compor um acervo de registros orais, dados, textos, fotografias e artefatos dos idosos inscritos na UnATI/UERJ; o anteprojeto de implantação do Centro de Referência e Documentação da UnATI, ${ }^{* *}$ que incluía, nos seus objetivos, que o acervo seria composto, entre

\footnotetext{
Elaborado por Alfredo Gomes Faria Jr., Fátima Malheiros e Jacqueline Ventapane em 1996.

"** Documento sem data, provavelmente elaborado antes de 1998, pois o CRDE/UnATI foi inaugurado em 1999 sob a coordenação da professora Shirley Donizete Prado
} 
outras coleções, da coleção de Memória Institucional.

O primeiro não chegou a ser executado, e o segundo, embora tenha sido implantado, não atingiu o objetivo de tratar a coleção do acervo de Memória Institucional. Assim, este Projeto toma a si o desafio de completar as metas não alcançadas em relação à organização dos materiais informacionais sobre a UnATI, agregando novos objetivos com vistas à criação do Centro Memória da UnATI.

O projeto Memória UnATI teve início em 2006, contando com a participação de um estagiário do curso de História. Sob a supervisão de uma bibliotecária especialista em Indexação e Recuperação da Informação, a presença de aluno do curso de História imprimiu um outro olhar sobre a questão da organização do acervo.

Em 2007, a Sub-Reitoria de Graduação da UERJ - SR-1 conferiu ao referido projeto o prêmio de menção honrosa em reconhecimento ao trabalho apresentado na $6^{\mathrm{a}}$ Semana de Graduação.

Esse projeto foi elaborado com o objetivo principal de organizar e preservar a Memória da UnATI, e, como objetivos específicos: resgatar os documentos históricos; analisar, identificar, registrar e indexar os documentos; criar uma base de dados com os materiais informacionais; coletar depoimentos, mediante roteiro de entrevista e gravação; criar um link na bome page da UnATI para o Acervo de Memória; manter um acervo de depoimentos no link Memória UnATI e definir um espaço, no CRDE, para o armazenamento dos diversos materi- ais em condições técnicas adequadas a cada tipo de material.

\section{METODOLOGIA}

O Projeto Memória está em execução nas instalações do CRDE. Em um primeiro momento, procedeu-se à leitura da literatura localizada e disponível para o embasamento teórico da pesquisa. A seguir, foram feitas pesquisas na Internet, visando à identificação dos centros de memória existentes e, para observação de experiências práticas, realizaram-se visitas técnicas a dois importantes setores da Universidade: o Núcleo de Memória, Informação e Documentação - MID, pertencente à Rede SIRIUS, e o Centro de Memória da Faculdade de Enfermagem, ambos com projetos bem-sucedidos de preservação da memória institucional.

No segundo momento, deu-se o desenvolvimento das ações para o processamento técnico dos materiais: identificação, análise e registro dos documentos existentes no CRDE. Após as primeiras ações, os dados foram registrados em um formulário com os seguintes campos: autor, título, data, assunto, palavras-chave, e outros elementos considerados relevantes para a identificação destes. Para a indexação dos documentos, utilizou-se um vocabulário controlado, elaborado a partir da lista de cabeçalhos de assunto do Bibliodata/CALCO e, em casos específicos, tomaram-se por base os princípios da garantia de uso introduzindo palavras extraídas do vocabulário dos profissionais e pesquisadores da UnATI. Foi criada 
uma base de dados" - utilizando o sistema Winisis -, para armazenar e recuperar, de for$\mathrm{ma}$ ágil, os documentos registrados.

Posteriormente, será coletada a documentação na forma de depoimento oral, material que será conservado e que fará parte do patrimônio da Universidade. Serão válidos tanto os depoimentos colhidos pela equipe do projeto quanto o material existente no acervo do Centro de Tecnologia Educacional - CTE, como aqueles originados de pesquisas para a elaboração de dissertações e teses. Nessa etapa, pretendese entrevistar profissionais e alunos que participaram do processo de criação $\mathrm{da}$ UnATI, mediante um questionário elaborado para a entrevista - este será o fio condutor para colher os depoimentos.

Em uma última etapa, as informações sobre a Memória Institucional da UnATI/ UERJ serão disponibilizadas na Internet, através do sítio da UnATI. Devendo-se também exibir os documentos históricos em área de destaque no CRDE e projetar o Centro de Memória, como centro produtor, receptor e difusor de material relacionado à UnATI/UERJ.

\section{RESULTADOS}

Desde o início da implementação do projeto foram registradas em livro-ata as decisões tomadas em reuniões e projeções das atividades a serem desenvolvidas. Com isso criou-se uma linha norteadora do trabalho nos seus diversos estágios, mantendo-se a continuidade.

Ao localizar documentos e reportagens relacionados à UnATI, foi possível organizar uma cronologia dos fatos que comprovam a criação e o desenvolvimento da Universidade Aberta da Terceira Idade da UERJ.

O Projeto vem atingindo seus objetivos, cumprindo as atividades programadas em relação à análise, seleção, indexação e registro dos materiais. No que diz respeito à coleta de depoimentos orais, está sendo feita a revisão de literatura para o embasamento das futuras ações.

Os documentos recuperados $\mathrm{e}$ indexados estão sendo incluídos na base Memória (figura 1). A base possui, atualmente, 231 registros disponíveis para consulta no CRDE. Foram registrados documentos de várias tipologias, como pode ser observado no quadro1.

O cronograma preestabelecido vem sendo cumprido e, atualmente, o projeto está sendo apresentado à comunidade interna, de forma a incentivar a sua participação na captação de materiais informacionais de interesse para o acervo da memória institucional.

\footnotetext{
A Base de dados Memória UnATI foi elaborada em 2007 por José Arturo Vilchez Cueva.
} 
Figura 1 - Base de dados Memória da UnATI/UERJ

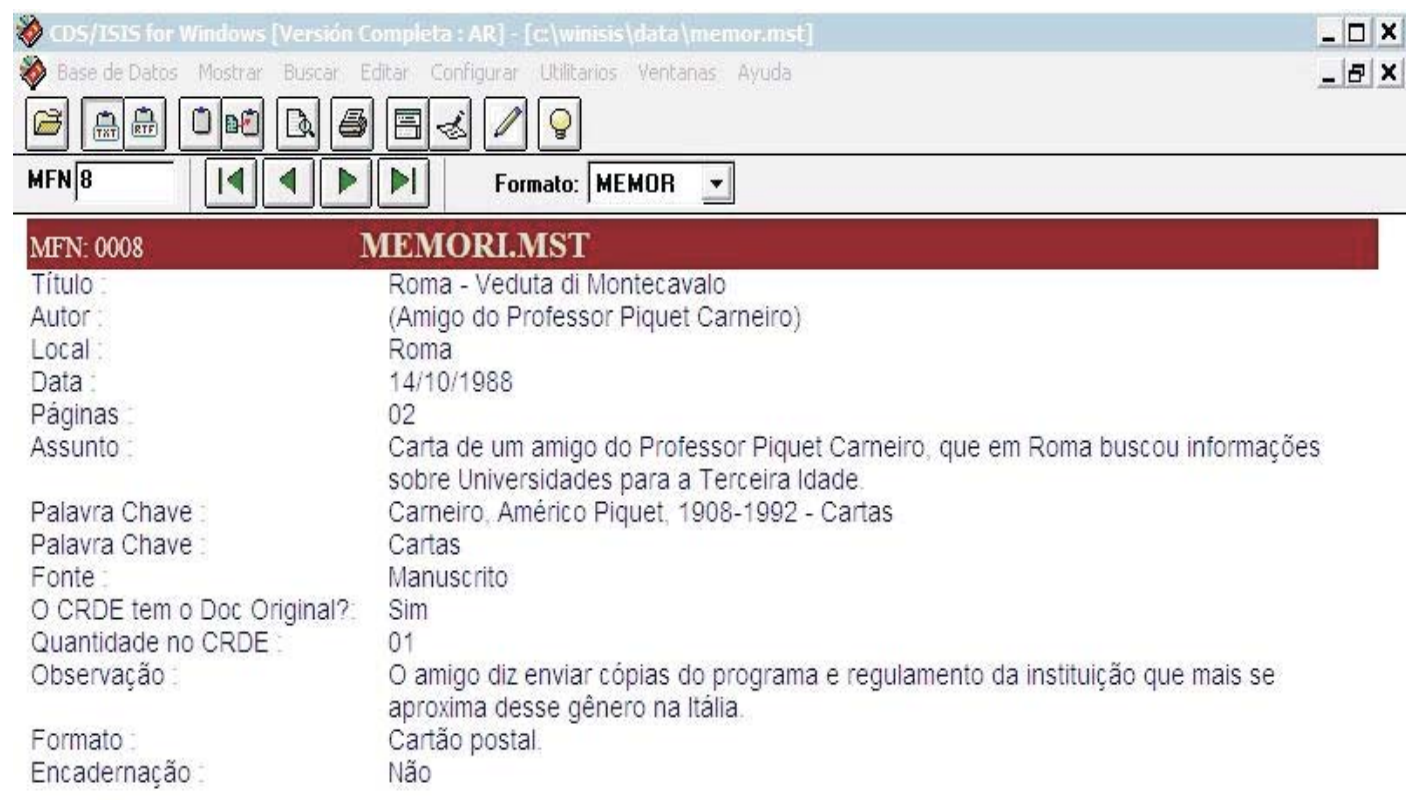

\footnotetext{
$\overline{\overline{\text { MAX: } 117}}$

CDS/ISIS 1.5 (build 3) for Windows - December 2003 - UNESC0 ๑ (Mode: SINGLE USER)
} 
Quadro 1 - Tipologia dos documentos registrados

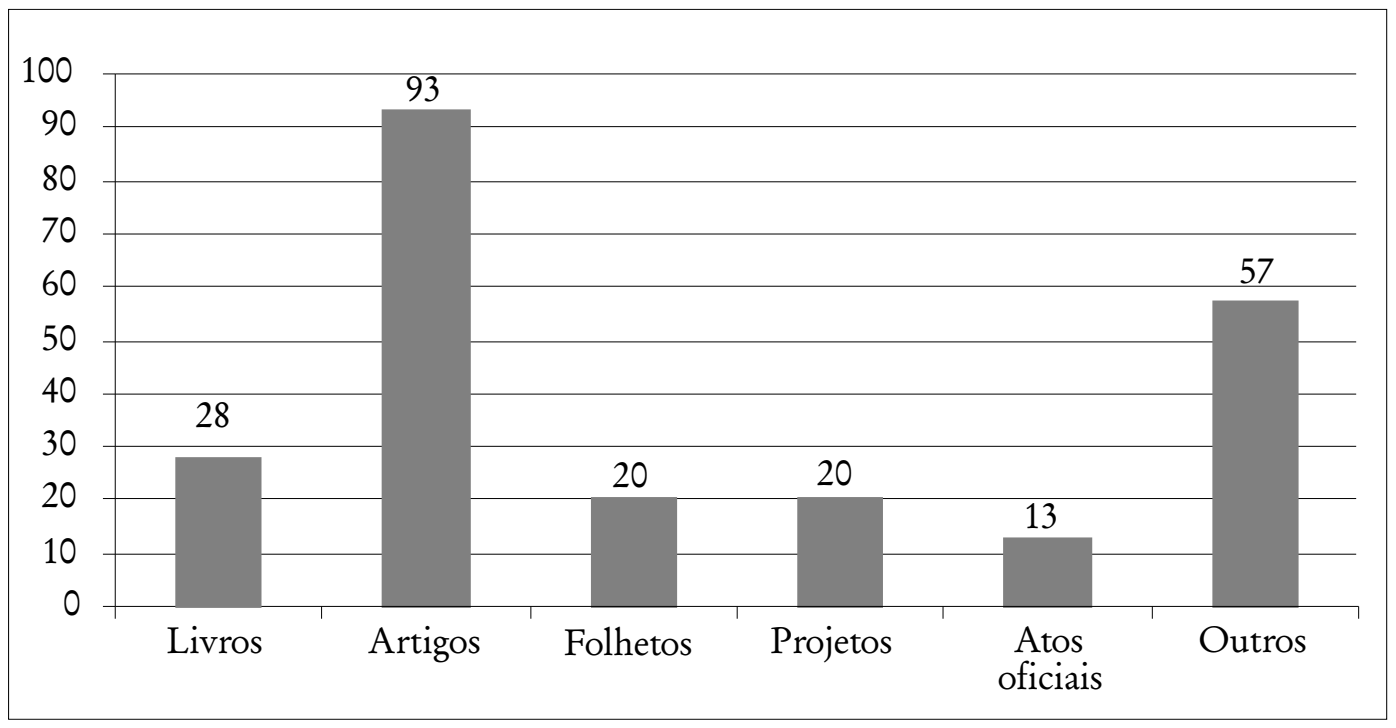

\section{CONCLUSÃO}

O histórico de criação da UnATI remonta a sua idealização pelo Prof. Américo Piquet Carneiro, o que ocorreu há 30 anos. Isto corresponde à metade do tempo de sua efetiva implantação. Às idéias iniciais foram agregadas outras, que transformaram a UnATI em um complexo espaço voltado à assistência integral do idoso, à qualificação de recursos humanos para atuar nesse espaço e ao desenvolvimento da pesquisa científica em envelhecimento humano.

Considerando-se que o modelo UnATI desperta a atenção de instituições e pesquisadores que buscam informações sobre seu processo de criação, desenvolvimento e manutenção, pretende-se que, ao identificar o cenário no qual foi criada a UnATI, ao re- gistrar os fatos na linha do tempo, ao recuperar documentos e colher depoimentos, a memória seja reconstruída e preservada.

Espera-se que a visibilidade desse modelo e a disseminação de sua memória possam contribuir para outras iniciativas, no Brasil, que privilegiem a questão do envelhecimento, suscitando debates, discussões e propostas, dentre outros.

\section{NOTAS}

\footnotetext{
Bibliotecária da Universidade do Estado do Rio de Janeiro, Coordenadora do Projeto Memória da UnATI/UERJ, Especialista em Indexação e Recuperação da Informação.

b Bibliotecária da Universidade do Estado do Rio de Janeiro, Núcleo de Processos Técnicos da Rede SIRIUS, Especialista em Organização do Conhecimento para a Recuperação da Informação pela UNIRIO.
} 


\section{REFERÊNCIAS}

1. Santos MS. Sobre a autonomia das novas identidades coletivas: alguns problemas teóricos. Revista brasileira de Ciências Sociais 1998; 13 (38). [acesso 2008 mar 01]. Disponível em: URL: http:// www.scielo.br/ scielo.php? script $=$ sci arttext $\&$ pid $=$ S010269091998000300010\&lng $=$ en\& $\& r m=$ iso.

2. World Population Ageing 2007. [acesso 2008 fev 22]. Disponivel em: URL: http:// www.un.org/esa/population/ publications/WPA2007/ES-Spanish.pdf .

3. Bosi E. Memória e sociedade: lembranças de velhos. 8.ed. São Paulo: Companhia das Letras; 1999.

4. Carneiro AP. Atualidades do envelhecimento dos povos. Boletim UERJ 1979; (152): 185- 200.

5. Veras RP; Caldas CP. Promovendo a saúde e a cidadania do idoso: o movimento das universidades da terceira idade. Ciência Saúde Coletiva 2004; 9 (2) : 423-32.

6. Portal Periódicos Capes. [acesso $2008 \mathrm{mar}$ 15]. Disponível em: www.periodicos.capes.gov.br

7. Abreu R, Chagas M, organizadores. Memória e patrimônio. Rio de Janeiro: DP\&A; 2003.

8. Benjamin W. A modernidade e os modernos. Rio de Janeiro: Tempo Brasileiro; 2000.

9. Caldas NP. A experiência da criação do Centro de Memória da Faculdade de Enfermagem da UERJ. Escola Anna Nery revista de enfermagem 2000; 4 (3): 347-57.

10. Le Goff J. História e memória. Campinas: Unicamp; 2003.
11. Lemos MTTB, Moraes NA, organizadores. Memória e construções de identidades. Rio de Janeiro: 7 Letras; 2000.

12. Medeiros JM. O Instituto de Economia/ UFRJ: memória e representação nos discursos e narrativas dos seus professores - 1979-1996. [mestrado]. Rio de Janeiro: Programa de Pós-Graduação em Memória Social. Centro de Ciências Humanas e Sociais, Universidade Federal do Estado do Rio de Janeiro; 2005.

13. Sá JLM. Universidade da Terceira Idade: fundamentos filosóficos, educacionais e epistemológicos. Campinas, SP: PUC; 1996.

14. Silva MCA, Velho AS, Santos RB.

Memória institucional: acervo fotográfico. [acesso 2008 jan 10] Disponível em: URL: http://www.sibi.ufrj.br/snbu/snbu2002/ oralpdf/93.a.pdf.

15. Universidade do Estado do Rio de Janeiro. Hospital Pedro Ernesto. Prof. Américo Piquet Carneiro. [ acesso 2008 fev 6]. Disponível em: URL: http://www.hupe.uerj.br/conheca/ homenag/piquet.htm.

16. Veras RP; Caldas CP. UnATI - UERJ - 10 anos : um modelo de cuidado integral para a população que envelhece. Rio de Janeiro: UERJ, UnATI; 2004.

17. Pollak M. Memória e identidade social. Estud Hist 1992; 5 (10).

18. Halbwachs M. A memória coletiva. São Paulo: Vértice; 1990.

19. Freitas FJ, Braga PLAM. Questões introdutórias para uma discussão acerca da história e da memória. [acesso $2008 \mathrm{fev}$ 20]. Disponível em: URL: http:// www.historica.arquivoestado.sp.gov.br/ materias/anteriores/edicao13/materia03/ texto03.pdf.

20. Meihy JCSB, Holanda F. História oral: como fazer, como pensar. São Paulo: Contexto; 2007. 
1 